\title{
The multiaxial yield behaviour of an aluminium alloy foam
}

\author{
I. SRIDHAR*, N. A. FLECK ${ }^{\dagger}$ \\ Cambridge University Engineering Department, Trumpington Street, \\ Cambridge CB2 1PZ (UK) \\ E-mail: naf1@eng.cam.ac.uk
}

The multi-axial yield behaviour of the aluminium alloy foam Alulight has been measured. Triaxial tests have been performed on a range of relative densities in order to compare the hydrostatic stress versus strain response with the uniaxial compressive response, and to probe the yield surface after prior hydrostatic compression. It is found that the degree of strain hardening in hydrostatic compression exceeds that for uniaxial compression, and the yield surface remains almost self-similar in shape after hydrostatic compaction. The measured yield surface provides support for the phenomenological yield model of Deshpande and Fleck (V. S. Deshpande, N. A. Fleck, Journal of Mechanics and Physics of Solids, 48, (2000), 1253). Upon reviewing the available experimental evidence from this and previous studies it is found that a broad correlation emerges between the relative density and the shape of the yield surface for metallic foams. (C) 2005 Springer Science + Business Media, Inc.

\section{Introduction}

Metallic foams are finding wide use in engineering applications for constructing lightweight structures, energy absorbing crush zones of automobiles, heat sinks for electronic devices and packaging. Some recent advances in the manufacturing, characterization and applications of metallic foams have been highlighted by Banhart [1], and a design guide by Ashby and coworkers [2] address the properties and industrial applications of metallic foams. Critical reviews on processing and potential applications of metallic foams are provided in the special issues of Advanced Engineering Materials (Vol. 2(4), 2000; Vol. 4(10), 2002; Vol. 6(6), 2004).

Complex-shaped metal foams with a greater control on microstructure can be obtained by adopting powder metallurgy techniques. Alulight foams are manufactured by mixing powders of titanium hydride $\left(\mathrm{TiH}_{2}\right)$ with aluminium and the alloying elements magnesium and silicon. The powder mixture is then extruded or rolled to give a bar with a relatively homogeneous distribution of hydrides. It is chopped into small pieces, and then heated into the solid-liquid molten state. As the metal solidifies, the titanium hydride decomposes, and foam is produced at a temperature below the solidus temperature. McCullough et al. [3, 4] have studied the monotonic and fatigue behaviour of these foams in uniaxial tension and compression. The test data reveal that for a given relative density, Alulight foams are the stiffest and strongest of other commercial closed cell aluminium foams.

In practice, foams may be subjected to multiaxial loads. Hence, a constitutive law describing the yield behaviour of these foams is essential for practical designs. The published data on the yield behaviour of foams are very limited, as triaxial experiments are notoriously difficult to perform. Multiaxial failure of an open-cell (Duocell) and closed-cell (Alporas) Al foams have been investigated by Gioux et al. [5] and Deshpande and Fleck [6]. In this study, the stress-strain response of Alulight foams is reported for both uniaxial and hydrostatic loading in compression. The Alulight foam is of a different composition and is made by a radically different process than that of Duocell and Alporas foams, and is a promising material within European industry. The yield surface is determined by probing a compacted specimen along selected stress paths in a triaxial test cell. Finally, the experimental measurements are compared with the phenomenological constitutive model of Deshpande and Fleck [6].

\section{Test material}

In this study, multiaxial tests are reported for a closedcell Alulight foam, ${ }^{1}$ manufactured by using a powder metallurgical route. Triaxial loading (isostatic load) tests and uniaxial compression tests have been con-

\footnotetext{
${ }^{1}$ Supplied by: Institute of Materials and Machine Mechanics, Sloval Academy of Sciences in collaboration with MEPURA GmbH, Austria.
}

\footnotetext{
* Present address: School of Mechanical \& Production Engg. Nanyang Technological University, 50 Nanyang Avenue, Singapore 639798.

$\dagger$ Author to whom all correspondence should be addressed.
} 


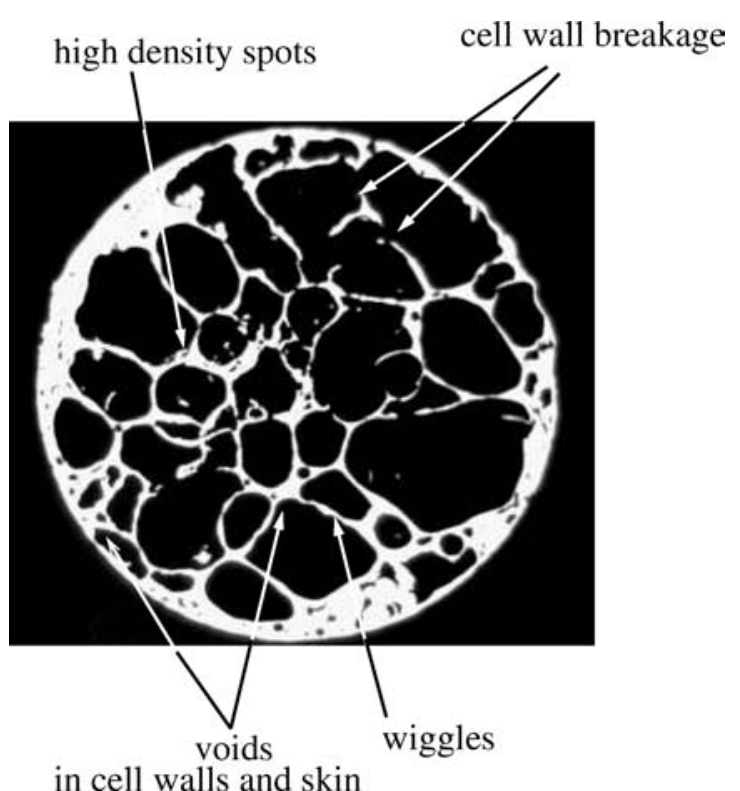

Figure 1 Optical micrograph of a typical Alulight foam specimen. The as-received bar is of diameter $16 \mathrm{~mm}$.

ducted on the aluminium alloy foam consisting of $0.6 \%$ $\mathrm{Mg}$ and $0.3 \%$ Si by wt., while yield surface measurements have been made on a slightly different foam of composition $1.0 \% \mathrm{Mg}$ and $0.6 \% \mathrm{Si}$ by wt. The asreceived samples were circular bars of diameter $16 \mathrm{~mm}$ and an average cell size of $2 \mathrm{~mm}$. The surface skin of the bars was much thicker than that of the cell walls, and the skin was removed by machining circular cylindrical samples to a diameter of $12.5 \mathrm{~mm}$ and a length of 25-27 mm. Electro-discharge machining (EDM) was employed in order to minimise damage to the cellular microstructure. The axis of the cylindrical bar was aligned with the rise direction of the foam.

An optical micrograph of a representative crosssection of the as-received bar is shown in Fig. 1. The morphological features of the Alulight foam are evident: the cell size is widely distributed, with 5 to 8 cells across the diameter. Onck et al. [7] have studied size effects in cellular solids and recommend at least six cells across the specimen diameter in order to achieve the bulk response. Consequently, the cylindrical specimen geometry is considered to be adequate for measuring the macroscopic hydrostatic compaction behaviour. ${ }^{2}$ It can also be noted from Fig. 1 that the cell walls are curved in shape and possess superimposed short-wavelength wiggles on some of the cell faces. There is a non-uniform distribution of cell wall material with voids within some of the cell wall, cell wall waviness, thickness variations and breaks. These imperfections are the major factors affecting the stiffness and strength of metallic foams [8-15].

\section{Experiments}

The initial density of the foam sample was calculated from the measured mass and dimensions of the specimen. The relative density was measured with respect to the density of solid aluminium, taken to be $2700 \mathrm{kgm}^{-3}$.

\footnotetext{
${ }^{2}$ Limitations on the internal dimensions of the pressure cell precluded the use of larger specimens.
}

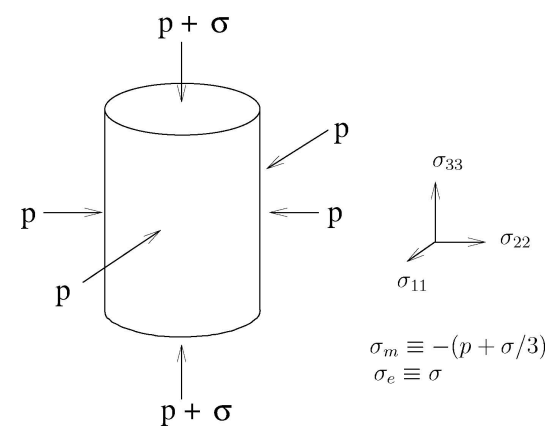

Figure 2 Axisymmetric loading on a cylindrical metallic foam specimen. The effective stress $\sigma_{e}$ equals $\sigma$, and the mean stress $\sigma_{m}$ equals$(p+\sigma / 3)$ where $p$ is the hydrostatic pressure and $\sigma$ is the additional axial stress on the specimen at yield.

Cylindrical foam specimens were wrapped with a $50 \mu \mathrm{m}$ thick aluminium shim, placed inside a flexible rubber tube and mounted in the triaxial pressure vessel $[16,17]$. A $20 \mathrm{MPa}$ hand-driven hydraulic oil pump was used to apply the hydrostatic pressure $p$ to the specimen. The triaxial cell was mounted on the cross-head of a screw-driven Instron testing machine and an additional axial stress $\sigma$ was applied to the specimen via a piston, as sketched in Fig. 2.

When the foam is loaded by hydrostatic pressure, compressive radial and axial strains are induced. The decrease in axial length was measured by a linear voltage displacement transducer (LVDT) mounted on the triaxial cell, and used to define the nominal axial strain. No direct measure of radial strain was available. An isotropic response was assumed, and the volumetric strain was taken to equal three times the axial strain.

Two types of test were performed as follows. First, proportional loading tests were done at a strain rate of $10^{-3} \mathrm{~s}^{-1}$ both in uniaxial and hydrostatic compression. Second, the current yield surface was probed in the following manner. The specimen was loaded hydrostatically to a volumetric compressive strain of $1 \%$; the specimen was then unloaded elastically by decreasing the confining pressure to a fixed value within the yield surface. The pressure was held constant, and an additional axial load was applied via the piston rod of the triaxial cell until the onset of yielding was determined. A plot of additional axial stress against uniaxial strain was used to determine the onset of yield. The axial yield stress was determined using a $0.04 \%$ offset plastic strain. This value of offset plastic strin was a compromise: it was sufficiently small to give negligible strain hardeing, yet was sufficiently large to lead to an unambiguous and repeatable measure of the yield strength. The specimen was then unloaded axially and the hydrostatic pressure on the specimen was decreased. The probing process was repeated so that the yield surface was obtained for a single specimen. The sum of the axial stress at yield $\sigma$ and the confining pressure $p$ was used to calculate the mean stress $\sigma_{m}=p+\sigma / 3$ and the deviatoric stress $\sigma_{e} \equiv \sqrt{\frac{3}{2} \sigma_{i j}^{\prime} \sigma_{i j}^{\prime}}=|\sigma|$, where $\sigma_{i j}^{\prime}$ is the deviatoric component of the stress tensor $\sigma_{i j}$.

\section{Results and discussion}

Measurements of the pressure-density response of Alulight foams are now presented for hydrostatic loading, 
followed by probing data for the yield surface in mean stress versus deviatoric stress space.

\subsection{Proportional loading tests}

Typical pressure versus volumetric strain curves are shown in Fig. 3a for selected values of initial relative density of the Alulight foam. The hydrostatic pressure versus volumetric strain response has three consecutive regimes: linear elastic, strain hardening plastic and densification with a high terminal strain hardening rate. The stiffness and strength increase while the densification strain decreases with increasing relative density.

In Fig. 3b, the uniaxial compressive response of Alulight foam is compared with that of hydrostatically compressed foam. The yield strength is comparable for uniaxial and hydrostatic loading, but the rate of hardening for hydrostatic loading is significantly greater than for uniaxial compression. This is similar to the behaviour for Alporas foams as investigated by Deshpande and Fleck [6].

\subsection{Yield surface measurement}

The yield surfaces for four different values of initial relative density, pre-compacted to $1 \%$ volumetric strain,

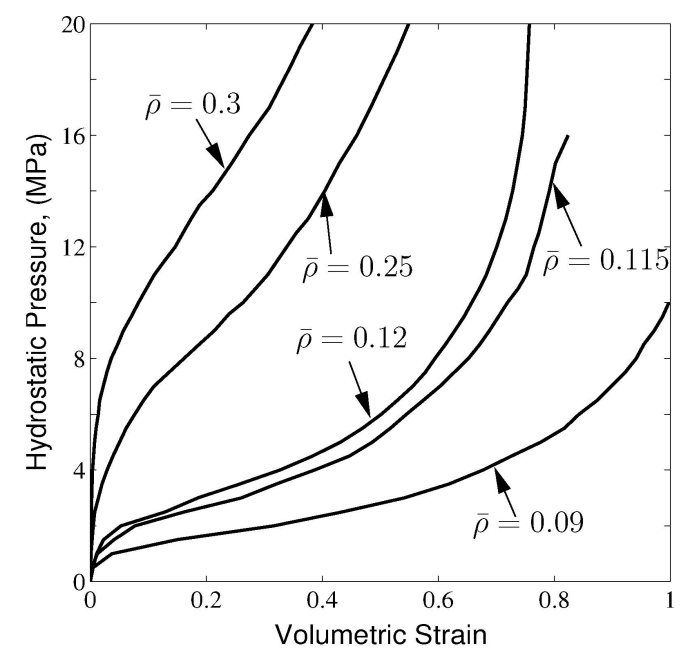

(a)

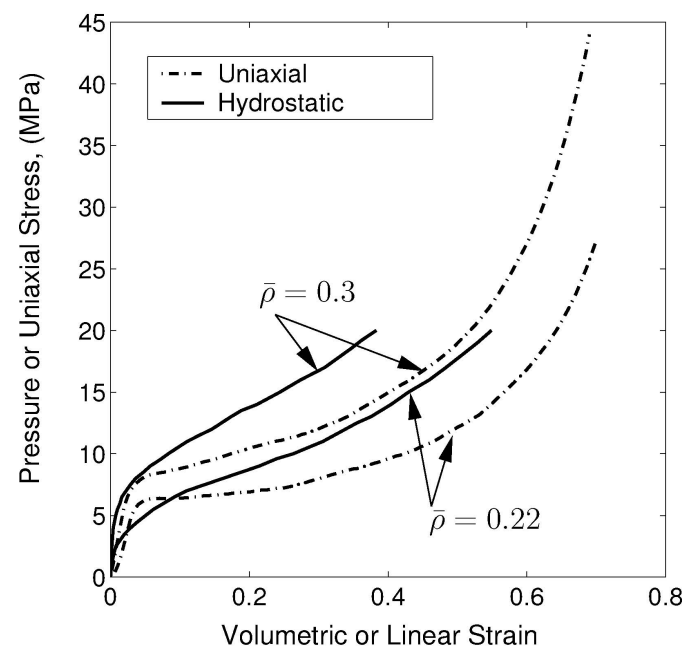

(b)

Figure 3 (a) Deformation response of Alulight foams of initial relative density $9 \%$ to $30 \%$ under hydrostatic compaction. (b) Uniaxial and hydrostatic stress-strain curves for Alulight foams.

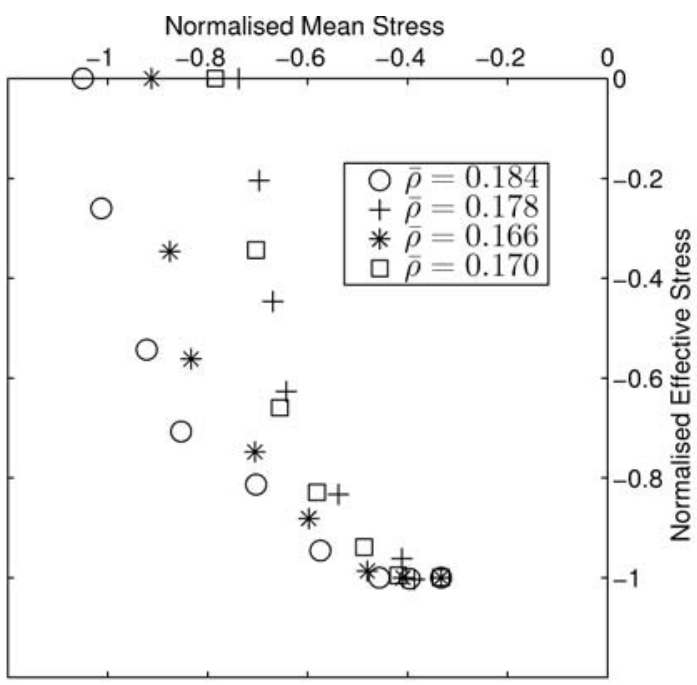

(a)

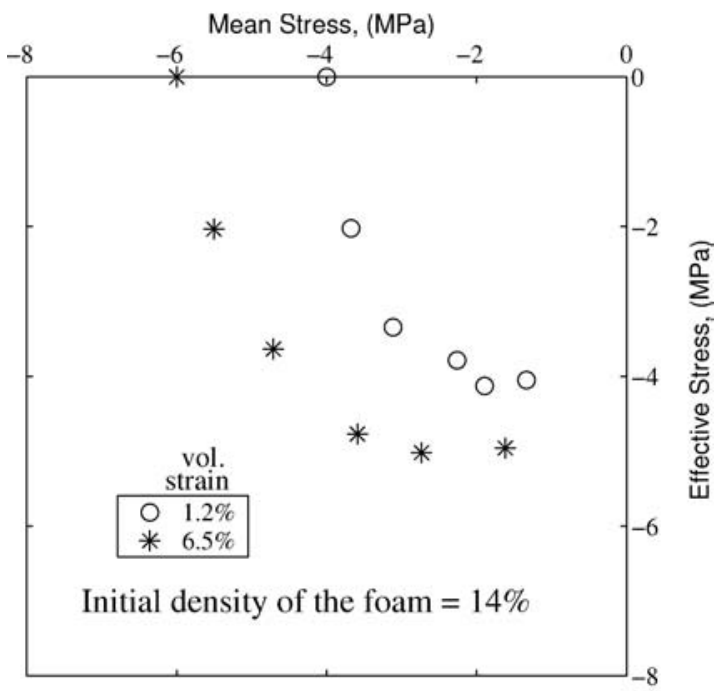

(b)

Figure 4 (a) Yield surface of Alulight foams after compaction to $1 \%$ volumetric strain. (b) Evolution of the yield surface of Alulight foam with the degree of hydrostatic compaction. The yield surface is shown after a volumetric pre-strain of $1.2 \%$ and $6.5 \%$.

are plotted in mean stress versus von Mises effective stress space in Fig. 4a. The stresses are normalized by the uniaxial yield strength of the foam in order to explore the effect of relative density upon the shape of the yield surface. In all cases the yield surface can be treated as elliptical in shape, with the ratio of hydrostatic strength to uniaxial strength in the range 0.7 to 1.1. The connectivity of cell struts at each node is sufficiently low for the foam to deform by cell wall bending under all loading directions [18].

The effect of volumetric pre-strain upon the size and shape of the yield surface is shown in Fig. 4b. The yield surface is shown for a foam of initial density $14 \%$ after a volumetric pre-strain of 1.2 and $6.2 \%$. The limited measurements on yield surface evolution shows that this foam hardens in an approximately isotropic manner: the yield surfaces are almost self-similar.

\subsubsection{Fit of Constitutive Law to the measured yield surface}

The Deshpande and Fleck [6] model for multi-axial yield of metal foams introduces a combined loading 
parameter in the form of the overall equivalent stress $\hat{\sigma}$, defined as

$$
\hat{\sigma}^{2}=\left[\frac{9}{9+\alpha^{2}}\right]\left(\sigma_{e}^{2}+\alpha^{2} \sigma_{m}^{2}\right)
$$

where the material parameter $\alpha$ describes the aspect ratio of the elliptical yield surface in von Mises effective stress $\sigma_{e}$ versus mean stress $\sigma_{m}$ space. Yield is activated when the yield criterion

$$
\phi=\hat{\sigma}-Y \equiv 0
$$

is met, with $Y$ as the current uniaxial strength of the foam. The Deshpande and Fleck model assumes isotropic hardening, such that the yield surface enlarges with plastic strain but remains geometrically selfsimilar.

In Fig. 5, an ellipse of the form 1 has been used to fit the yield data for the Alulight foams after an initial volumetric compression of $1 \%$. It is concluded that the simple constitutive description gives an adequate fit to the measured yield surfaces.

It is instructive to plot $\alpha$ as a function of the relative density $\bar{\rho}$ for the Alulight foam, and include the data from Deshpande and Fleck [6] for Alporas and Duocel foams (see Fig. 6). A broad correlation emerges with $\alpha$ decreasing from a value of about 2 to 1 as $\bar{\rho}$

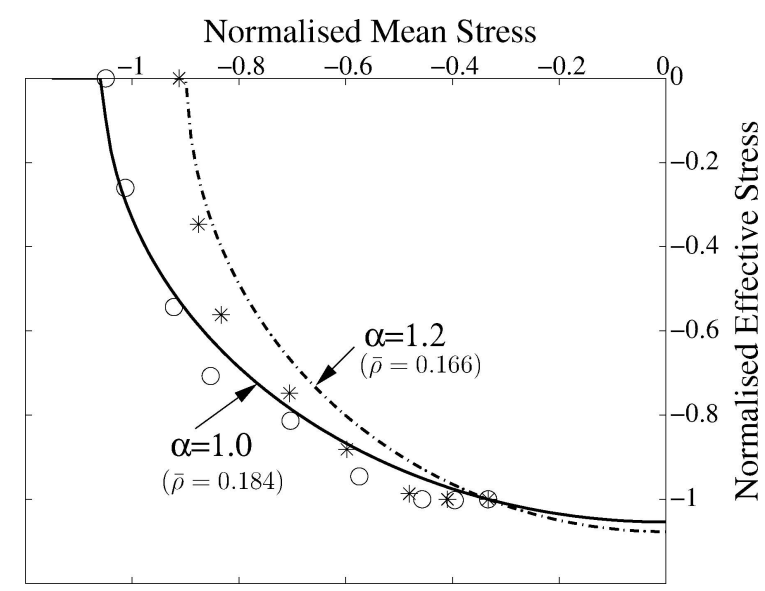

Figure 5 Fit of the Deshpande-Fleck quadratic yield surfaces to the measured yield surface of Alulight foam, after a volumetric pre-strain of $1 \%$.

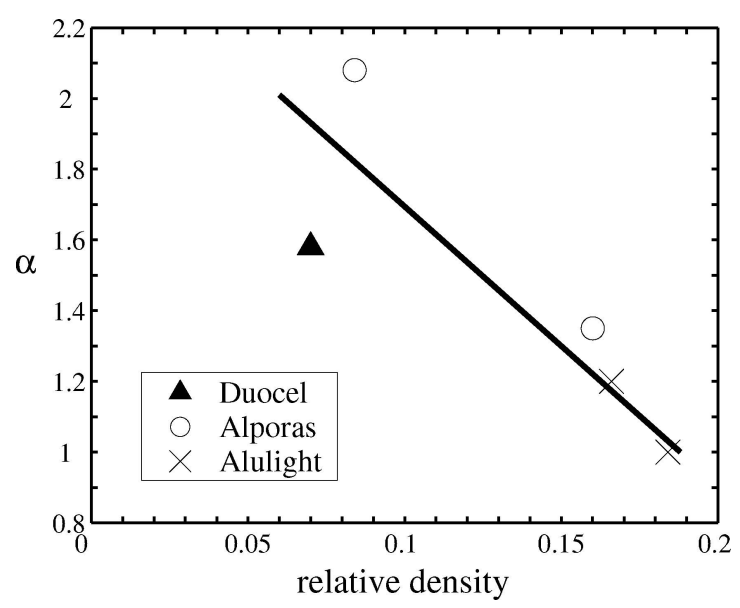

Figure 6 Dependence of aspect ratio of elliptical yield surface $\alpha$ upon the relative density $\bar{\rho}$ for a range of metallic foams. increases from 0.08 to 0.20 . In the limit $\bar{\rho} \rightarrow 1$, the plastic response becomes incompressible and yield becomes insensitive to pressure, and $\alpha \rightarrow 0$.

\section{Conclusions}

The hydrostatic compaction response of Alulight has been investigated by subjecting a cylindrical specimen to triaxial pressure loading. The main findings are summarized as follows.

1. The pressure versus volumetric strain response has three distinct regimes, similar to uniaxial compressive stress-strain curve: an initial linear elastic regime, strain hardening plastic and finally densification. The degree of strain hardening in hydrostatic compaction exceeds that obtained in uniaxial compression (see Fig. 3b).

2. The observed yield surface of Alulight foam can be represented by an ellipse in mean stress versus effective stress space in support of the phenomenological constitutive model of Deshpande and Fleck [6].

\section{Acknowledgements}

The authors are grateful to Dr. V. S. Deshpande for advice during the course of this research. Funding for I. Sridhar from Cambridge Commonwealth Trust (Nehru Fellowship) is gratefully acknowledged. The authors are grateful to ONR for financial support through USONR IFO grant number N00014-03-1-0283.

\section{References}

1. J. BANHART, Progr. Mater. Sci. 46 (2001) 559.

2. M. F. ASHBY, A. G. EVANS, N. A. FLECK, L. J. GIBSON, J. W. HUTCHINSON and H. N. G. WADLEY, "Metal Foams: A Design Guide" Butterworth-Heinemann, Boston 2000.

3. K. Y. G. MCCUllough, N. A. FleCK and M. F. A S HB Y, Acta Mater. 47 (1999) 2323.

4. Idem., Fat. Fract. Eng. Mater. Struct. 23 (2000) 199

5. G. GIOUX, T. M. MCCORMACK and L. J. GIBSON, Int. J. Mech. Sci. 42 (2000) 1097.

6. V. S. DEShPANDE and N. A. FLECK, J. Mech. Phy. Sol. 48 (2000) 1253.

7. P. R. ONCK, E. W. ANDREWS and L. J. GIBSON, Int. J. Mech. Sci. 34 (2000) 681.

8. Y. SUGIMURA, J. MEYER, M. Y. HE, H. BARTSMith, J. GRENESTEDT and A. G. EVAns, Acta Mater. 45 (1997) 5245.

9. O. B. OLURIN, N. A. FLECK and M. F. ASHBY, Mater. Sci. Eng. A291 (2000) 136.

10. A. E. Simone and L. J. Gibson, Acta Mater. 46 (1998) 3929.

11. Idem., ibid. 46 (1998) 2139.

12. J. L. GREnestedt, J. Mech. Phy. Solids 46 (1998) 29.

13. J. L. GRENESTEDT and K. TANAKA, Scripta Mater. 40 (1999) 71.

14. J. L. GRENESTEDT and F. BASSINET, Int. J. Mech. Sci. 42 (2000) 1327.

15. A. E. MARKAKI and T. W. CLYNE, Acta Mater. 49 (2001) 1677.

16. I. SRIDHAR and N. A. FLECK, ibid. 48 (2000) 3341.

17. I. SRIDHAR, Mech. Powder Compact., Ph.D. Dissertation Report, University of Cambridge (UK), 1999.

18. V.S. DEShPANDE, M.F. ASHBY and N. A. FLECK, Acta Mater. 49 (2001) 1035. 